\title{
The Library Lobby
}

\begin{abstract}
The importance, function, and utility of a university library is considered from the (jaundiced?) viewpoint of a computer scientist. The library is examined as partly a university-wide resource and partly as a research facility analogous to laboratory equipment in order to draw some conclusions about whether resources allocated to university libraries are appropriate. The position and breadth of use of the library relative to computing facilities is also considered as is the cost and value of library usage in relation to computer usage.
\end{abstract}

\section{"T}

HE COLLEGE LIBRARY should be the most important intellectual resource of the academic community" ("Standards for College Libraries," CRL, July 1959, p.274). In 1959, when this was written, the library was almost the only general intellectual resource at a college or university. Computers were barely beginning to be important at universities and the battery of instructional communications gear so familiar today was not a major factor on most campuses. Today, the library is still the most important resource of the academic community. I emphasize this point at the outset to try to avoid misunderstanding later. But the question is: Is the college or university library as preeminent as the library lobby-the librarians, accreditors, and their allies-would have us believe? If it is still the most important academic resource, how long will this be true? Is the portion of the university budget devoted to libraries in relation to the other academic resources reasonable? Most basic of all: What is the utility-if one can dare to talk in such terms-of most of the holdings of a university library?

Mr. Ralston is chairman of the Department of Computer Science of the State University of New York at Buffalo.
My general thesis is that relatively, if not absolutely, the value of much of university libraries is overrated and that, particularly in times of dwindling resources, the university library must no longer be considered sacrosanct, that its claims on the university budget need to be questioned as much or more than competing claims.

\section{The Library LobBy}

The power of the library lobby manifests itself both actively and passively. On the active side I had a glimpse of the power recently when I spent two days at a new, small college as a consultant on computer education and computer usage problems. It was depressing but not too surprising to find that the computing budget was negligible, particularly when contrasted to a library budget twenty to thirty times greater. Although there was a lack of perception of the present and growing importance of computers in all phases of the academic process, this was not the main reason for the relative sizes of the computing and library budgets. Rather, the college is hell bent for accreditation and thus is forced to give high priority to building the 50,000-volume collection necessary for accreditation. 
Another positive indication of the power of the library lobby may be found in the budget of the State University of New York and likely other public institutions also, where the appropriation for the libraries at the various campuses is a line item separate from the rest of the budget for the State University. Although such special treatment could cut both ways, in practice, there is no question that this treatment works for the benefit of the libraries by cushioning them from budget competition with the rest of the university.

Recently (March 1971) in the Communications of the Association for Computing Machinery there was an article reporting on a meeting last fall in Houston of the ACM Special Interest Group on University Computing Centers to discuss the problem of resource allocation and charging for use in university computing centers, a topic of no small interest to academic computing people in times of level or declining university budgets and declining federal support. A main point of debate at this meeting was whether a college or university computing center should be run on the bookstore model (charge users for all services, either directly or through departmental budgets) or the library model (let the computing center be a free resource for all without external funding up to the capacity of the facility). The arguments on the two sides are not relevant here. What is relevant is that one never seems to hear arguments about operating a library on the bookstore model! Charge every student or faculty member for every service including borrowing a book? Or, let each department have a budget for library usage against which each transaction would be charged? Perish the thought! The value of the library in the educational process cannot be measured by such techniques as charging for services. Or can it?

\section{The Three Faces of University LIBRARIES}

One of the barriers to appropriate perception of university libraries is its description as a general intellectual resource for the entire university community. Such a description is in fact much more applicable to a university computing center in which all users make use of approximately the same set of resources-the computer and its associated peripheral hardware. But only a minor portion of a university library-that part which serves general undergraduate education-contains resources used by a wide variety of people. Most of the remainder of the library consists of:

(1) Departmental fiefs, sometimes but rarely used by anyone except faculty, graduate students, and undergraduate students in one or, at most, a very small number of departments; and

(2) individual research fiefs where the book holdings and perhaps periodical back issues and subscriptions also are provided-often at great expense-for the research needs of one faculty member or a small group of faculty members.

If the above language sounds pejorative, that is not because I am opposed to research holdings in libraries; I'm not of course. Rather, my point is that the narrow utility of such holdings is seldom admitted.

On many campuses, indeed, the university library holdings are fragmented into smaller libraries, often departmental libraries. On others, such departmental libraries have been fought for but the proponents of central facilities have won. In my context the important point is the existence of the controversy which at least implies the nearly local nature of much of the holdings of a university library. It is, by the way, interesting to note that those who favor departmental libraries usually still wish 
the local library to be not only administered by the university staff but also supported by it. Departments are usually interested in library budgets only to the extent that funds are available in the university library budget for specific support of their needs.

The contrast with computing is interesting. Departments may have their own computers but they almost always both administer and support them themselves. This contrast between libraries and computers was probably reasonable when generous federal funding was available for the latter but not the former. But this is no longer the case and a closer congruence between administration and support for departmental libraries and computers seems to be in order.

Library collections-books and periodicals-which support fairly narrow research activities account for a significant portion of library expenditure including some of the most costly on a per book or journal basis. It needs to be recognized that such collections are quite analogous to the laboratory equipment so important to the research of scientists and engineers. Again, it is true that, in the halcyon days of massive federal funding for laboratory equipment, no valid argument could be made for considering library collections oriented toward specific research areas analogously with laboratory equipment. But times have changed and now more thought should be given to treating some library acquisitions and expenditures in a manner similar to laboratory equipment.

My conclusion then is that the support of university libraries should be looked at in three parts: (1) That which truly supports a university-wide academic resource; (2) that which mainly supports departmental needs rather than wider needs; and (3) that which mainly supports individual research.

It is clearly not simple to assign each item in a university to one of these three categories. Indeed, it is clearly not in the interests of those for whom parts of a library serve as little more than personal research collections to make this distinction. The result is often individual or departmental demands, particularly at growing universities, for increases in collections in certain areas which just bear no relation to the general academic function of the department. I heard recently of a humanities department chairman who claimed that a minimum of $\$ 750,000$ was needed to bring an already substantial collection up to snuff. It was not clear whether he thought his faculty or students really needed to read any substantial part of this material or whether the tactile pleasure which would be gleaned from handling the books was the real point. In any case, such requests are only possible because we have lost control of the place of libraries at universities. Only when we get this under control will the insatiable demands of university libraries for funds be put in a perspective where they will no longer result in deprivation of other parts of the university.

Now it is surely impractical to physically divide the library budget into three parts as implied by the categories above. But it is not impractical to estimate the approximate parts of the library budget attributable to each area and to make budgetary decisions based on this. In particular the total university resources available for departmental support and research support should include the funds now used to support the latter two categories above. Departments should be able-perhaps should be forced-to choose how much of the total support available to them should be spent on libraries. From another point of view, some of the funds expended for other than university-wide library support might be diverted to support such university-wide resources- 
and not just in libraries-or vice versa.

\section{The UtiLITY OF A UNIVERSITY LIBRARY}

Let us admit that it is surely very difficult to measure the value to a university of a book or a collection of books. Indeed, it is widely felt that attempts to attach such values to any facet of the academic process is antithetical to it; education may be a product but who has the temerity to place a value on it or its components? Yet one of the reasons for the current financial problems of universities is their failure to establish priorities. And such priorities can only be set by attempting, at least in a relative sense, to measure the value, the utility of allocating resources among conflicting competitors.

The single most important point to make about the utility of the books in a university library is that this varies greatly among the collection. Coupled with this is the fact that very few, if any, libraries consider the utility of a particular book or periodical when ordering it. There are, for example, those libraries which have standing orders into major publishers for everything they publish and which subscribe to almost every periodical in print. Now it is true that often one cannot fairly judge the value of a particular book or periodical. The sum of a library's holdings in an area may be greater than its parts because, for example, it may provide an environment conducive to research where a smaller holding will not. Still this does not gainsay the fact that large portions of most library collections are not only unused but, more important, are such that there is low probability that they will ever be used.

Moreover, the costs of using a university library are seldom calculated and are, in fact, much greater than most people realize. For example, a recent survey of major university libraries
(CRL, Jan. 1970, p.28-35) indicated that the ratio of total library expenditure to the volume of general and reserve circulation indicates a cost of about $\$ 4.00$ per book circulated. Now, of course, this isn't really a fair number. Libraries are not just circulators of books. Many people work in the library itself. Still, however one looks at it, the cost of providing service to its users is high. Corresponding figures for computing centers are hard to come by but, as an example, the University of Colorado charges a minimum cost of $\$ .60$ (which includes $\$ .20$ representing the rent charged by the university to the center) for each job run. This minimum cost is in fact the actual cost for most jobs, particularly those run by students.

Now who has ever thought of comparing the educational or research value of borrowing a book or periodical from a library and running a program on a computer? Maybe the values are incommensurate. But unless there is an attempt to make such value judgments, it is difficult to see how any rational decisions can be made on the allocation of resources to libraries and computing.

\section{The Breadth of Usage of A UNIVERSITY LIBRARY}

There should be no university discipline which does not make some use of a university library. But the amount of usage and library requirements are widely disparate. Whereas an historian may need to study broadly and deeply in a collection of books and documents, many scientists require libraries only quite occasionally and then for very specific, directed study to a single book or periodical. Therefore, whereas for teaching purposes the reserve collection may be very important to scientists, their research needs may be much more limited. In terms of its value to their work, the library may be quite secondary to many scientists (and others). Of 
much more importance may be their own laboratory equipment and computing facilities.

By contrast, the use of university computing facilities is not yet nearly so widespread for teaching or research as the use of the library. Outside the physical sciences, engineering, and the social sciences many departments make no use at all of computing facilities. It is easy to predict that the rapid spread of the use of computing throughout the academic process will continue until it will be a rare student and rare researcher who does not have contact with computing. But a more important point is that the number of departments to which the computer is vital for teaching and research is not significantly different from those to which a major library is vital. Thus, if a library is still the most important academic resource on a college campus, it no longer stands by itself, far more important than the computing resources.

From the point of view of immediacy, computing facilities on campus are even more important to those who need them than is a comprehensive library to those who require it. Lack of adequate computing facilities or fast service can be a severe, sometimes fatal impediment to effective research activity. Use of offcampus facilities is often not a reasonable alternative for both cost and logistic reasons. The lack of a specific book or periodical at a particular instant seldom causes similar difficulties. Admittedly, the efficiency of interlibrary loan procedures leaves much to be desired, but it is relatively unusual for the lack of specific items in the university library to make a research activity unfeasible. Also, when this is so, the needed item or items are likely to be of the very rare and/or expensive kind which puts them in the class analogous to laboratory equipment rather than in the class of a university-wide resource.

Thus, those parts of university li- braries which truly serve as universitywide resources are on the one hand quite comparable in breadth of usage to a computing center and, on the other hand, by no means the whole of the library.

\section{Libraries and the New Technology}

I have studiously avoided thus far any arguments based on the effect of computer and communications technology on libraries. I believe it would be necessary to reconsider the relative position of libraries and computing facilities even if there were no indication of a significant impact by this technology on the structure of a library and how it transacts its business. And let us admit that the impact of this technology looks much less profound or at least much further in the future than many computing people felt just a few years ago. But, for example, rapid long-distance facsimile reproduction, such as by long-distance xerography, is not too far away from becoming economic. When it is, the argument for extensive duplication of back periodical holdings or even current specialized periodicals will decrease considerably. All that need be said here is that none of the foregoing arguments require any of the new technology to be valid, but all will be strengthened as the new computer and communications technology becomes available and economic.

This article is a plea for a reconsideration if not a reevaluation of the relative place of a library in a university. It is a plea to make this reconsideration in an atmosphere free of the shibboleths of the past or the vested interests of the present. Although it is clear that I believe the result of such a study would be to downgrade this still most important resource, I believe even more strongly that universities must reassess their commitments in all areas if they are to survive the current parlous times in as good shape as possible. 